\title{
The effect of distribution of trials upon the habituation of tonic immobility in the tarantula, Aphonopelma californica
}

\author{
F. T. CRAWFORD \\ Florida State University, Tallahassee, Florida 32306
}

\begin{abstract}
Three groups of four tarantulas, A. californica, were examined for the effect of distribution of trials on the duration and induction frequency of tonic immobility. Group 1 received 12 trials/day for 2 days, Group 2 received 4 trials/day for 6 days, and Group 3 received 1 trial/day for 24 days. The differences between the three groups with respect to mean number of induction trials were not significant. However, the differences between the mean $\log$ duration times for the three groups were significant $(H=7.9, p<.02)$, indicating that the greater the distribution of trials, the greater the degree of habituation.
\end{abstract}

The expression "tonic immobility" refers to a state of immobilization that may be induced in animals by a variety of methods. Among these, the most common are inversion, restraint, the use of repetitive stimuli, novelty, and pressure on body parts. The immobility state is accompanied by certain body postures, changes in heart rate and respiration, pupillary responses, modification of EEG activity, and, among certain animals, changes in body color. Tonic immobility has been described by a wide variety of terms, including animal hypnosis, catalepsy, death feigning, and immobilization reflex. The measures of the effect reported most often have been duration of the state, induction latency, the number of trials or the frequency of success of induction, and the stimulus required for termination. The stimulus for termination either has been self-paced, that is, "spontaneous," or has been measured in terms of intensity. Among the behavioral effects noted is a decrease in duration of the state with repeated trials, accompanied by an increase in the induction latency and/or the frequency of successful induction. These effects are, in turn, influenced by the distribution of trials, in that the effects are minimized by a short intertrial interval for a given number of trials. A review of these considerations and other factors affecting tonic immobility may be seen in Crawford and Prestrude (1977), Gallup (1974), Gilman and Marcuse (1949), Klemm (1971), Ratner (1967), and Volgyesi (1966). The reports of tonic immobility in spiders as given by the above references are concerned primarily with the "mesmerism" involved in courtship behavior, and also with the deathfeigning response (see also Rabaud, 1919). Ternes (1977) has reported a circadian susceptibility to tonic immobility in the tarantula, Cyrtopholis portoricae.

The research was supported in part by NIMH Training Grant MH-11218. Portions of the data were presented at the Psychonomic Society meeting in Saint Louis, 1971, and appear in Crawford and Prestrude (1977).
The purpose of the present experiment was to investigate the effect of distribution of trials on the duration and induction frequency of tonic immobility in the tarantula.

\section{METHOD}

\section{Subjects}

Three goups of four tarantulas, Aphonopelma californica, were used in the study. They were obtained from a commercial animal supply house and had been maintained in the laboratory for over 12 months prior to the beginning of the experiment. During those 12 months, the tarantulas had served as subjects for two undergraduate research projects in comparative psychology courses, but they were naive with regard to the present study. The tarantulas were housed individually in enclosed aquaria, and their diet consisted of meal worms, crickets, and water. All 12 subjects tested were females.

\section{Procedure}

The subjects were tested in a piece of apparatus that was normally used to transport the spiders when it was necessary to move them, clean their living quarters, and so forth. The apparatus was an aluminum tube $7.5 \mathrm{~cm}$ in diameter and $12 \mathrm{~cm}$ long, closed at one end with a plastic cap. The cap had a hole drilled in it to accommodate a .7-cm-diam rod attached to a plastic insert that served as a piston within the cylinder. The piston rod had a handle that, falling against the plastic cap, kept the rod from falling out and limited the extension of the piston to within $.5 \mathrm{~cm}$ of the bottom of the cylinder. When a spider was to be picked up, the piston was withdrawn to its maximum, and the cylinder was placed over the spider. In this situation, a tarantula will typically press its legs against the cylinder wall and may be moved readily from one location to another without being touched by the experimenter. The subject may be removed from the cylinder by gently pushing the piston and forcing the tarantula out of the cylinder.

Tonic immobility was induced by placing the cylinder, with the piston withdrawn, over the spider, and then rapidly inverting the cylinder so that the spider was dorsal side down and remained immobile. (A more simple technique, also useful for demonstration purposes, employs a shallow, straight-sided drinking glass.) Termination of the tonic immobility state was indicated by the spider's righting itself within the cylinder. The duration of tonic immobility was measured with an Omega Speedmaster. 
The three groups of tarantulas each received 24 trials of tonic immobility. One group received 12 trials/day for 2 days, the second group received 4 trials/day for 6 days, and the third group received 1 trial/day for 24 days. If tonic immobility was not induced in a subject after six attempts, the trial was terminated and recorded as being of zero duration. All the data were collected over a 24-day period.

\section{RESULTS}

Duration of the tonic immobility state for all subjects over the total number of 24 trials is shown in Figure 1. The data are reported in log means, a common procedure in tonic immobility studies because of the great variability between and within subjects. The results indicate that the habituation effect reported for many other orders of animals also holds for the tarantula. Similar curves for the three subgroups within the experiment are shown in Figure 2. The subjects in Group 1 which received 12 trials/day for 2 days, show some habituation, but much less so than the other two groups of subjects. It may be noted that, after the first block of 12 trials, there is a slight rise on Day 2 in the mean $\log$ duration for Group 1. This may represent a "spontaneous recovery" of habituation to tonic immobility. The subjects in Group 2, which received one block of 4 trials/day for 6 days, show a rather regular decline in $\log$ mean duration of the tonic immobility state, but the greatest decline in effectiveness is observed in Group 3, which had the maximum distribution of trials within the present experiment ( 1 trial/day for 24 days). The differences between the groups, when tested by the Kruskal-Wallace nonparametric test of significance, yielded the value $H(2)=7.9(p<.02)$ for the mean number of seconds across blocks of trials in each group. Thus, it appears that, for the duration of the tonic immobility state at least, the greater the distribution of trials, the greater the degree of habituation.

The mean number of induction trials for the three groups combined produced an essentially flat curve, indicating no change in susceptibility to immobilization across trials. The mean number of induction trials

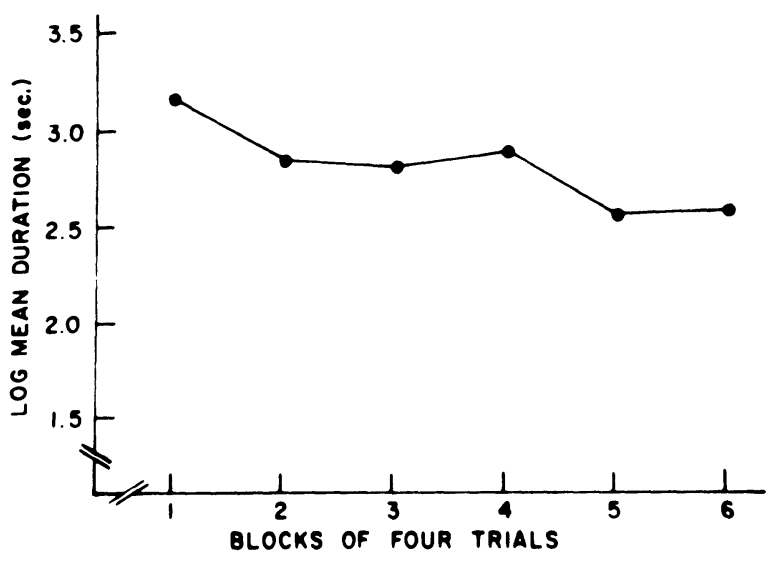

Figure 1. Log mean durations for all subjects across trials.

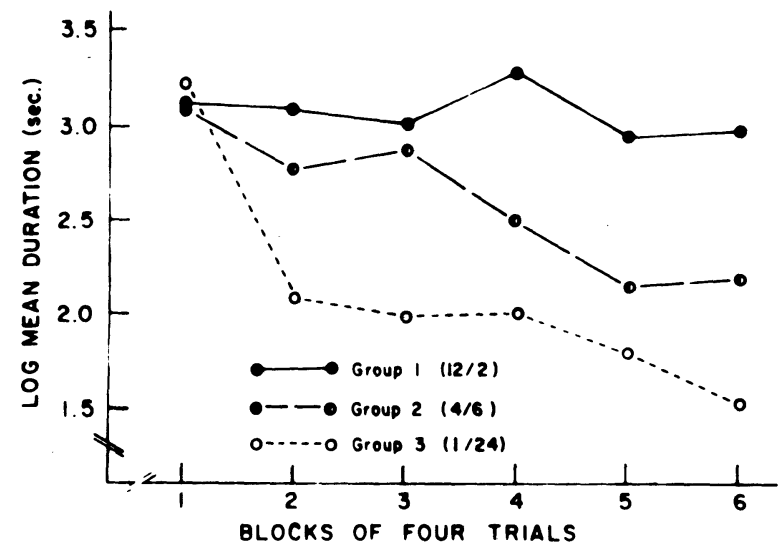

Figure 2. Log mean durations across trials for each of the three subgroups.

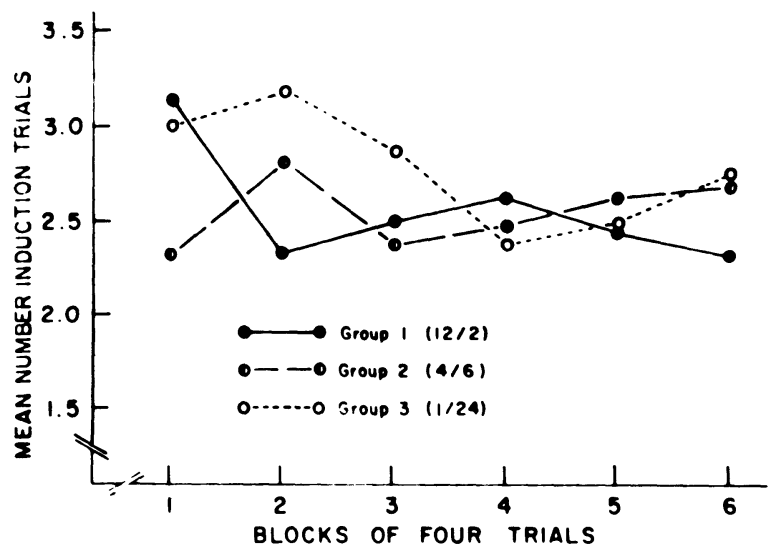

Figure 3. Mean number of induction trials for the three subgroups.

required for each of the three subgroups is shown in Figure 3. Although the curves show some degree of initial separation, the differences between the groups are not significant when tested by Kruskal-Wallace nonparametric analysis.

\section{DISCUSSION}

In the present experiment, tonic immobility was induced principally by inversion, although the characteristics of the cylinder were such that a minimal amount of restraint, selfimposed by the tarantula, seemed to be operating, in that the tarantula pressed its legs against the walls of the cylinder in order to support itself. The cylinder also served the function of reducing the opportunity for the spiders to observe the experimenter, which, according to studies reported by Gallup (1977), should have served to attenuate the durations of tonic immobility. The typical orientation of the spider while inverted during the tonic immobility state was to have the head lower than the rest of the body. During tonic immobility, the spiders were extremely immobile, and when they did recover, they would spread their limbs, stretch out, and upright themselves. During the experiment, there was the subjective impression that the subjects became more resistant to being picked up and more resistant to being inverted, even though the curves for frequency of induction do not reflect this.

Although the results of the experiment seem to verify the 
fact that distribution of trials is an important variable influencing the duration of tonic immobility, they also seem to indicate that induction is not affected or that, as employed as a criterion in the present experiment, induction is not a good measure of the immobility state. The curves for the log mean duration for each of the three groups (Figure 2) appeared to show a seeming regularity of function, but it should be pointed out that the long-duration trials were randomly dispersed throughout the total number of 24 trials, and that the "habituation" was apparently a group phenomenon and not necessarily characteristic of a given subject. Some subjects were much more susceptible than others, and each subject seems to have a position of inversion that is more conducive to inducing the immobility state than other positions. The inability of the experimenter to put the subject in a most favorable position to induce immobility may be the causal factor for the random distribution of durations found in the data. Examples of the problem are shown in some of the longer times recorded for subjects in different groups. For example, in Group 1, Subject 17 required $2 \mathrm{~h}, 22 \mathrm{~min}$, and $27 \mathrm{sec}$ to recover from the immobility state on Trial 14. Periods of over $2 \mathrm{~h}$ occurred on Trials 8 and 12 but on no other trial for this particular subject was there a duration of over $1 \mathrm{~h}$. The longest duration for Subject 8 in Group 1 occurred on Trial 19 and was $1 \mathrm{~h}, 30 \mathrm{~min}$, and $49 \mathrm{sec}$. For Subject 20 in Group 1, Trial 2 had a duration of $1 \mathrm{~h}$ and $19 \mathrm{sec}$, and this was approximated only by Trial 23, which had a duration of $1 \mathrm{~h}$, $10 \mathrm{~min}$, and $23 \mathrm{sec}$. Subject 3 in Group 1 had durations of $1 \mathrm{~h}, 48 \mathrm{~min}, 2 \mathrm{sec} ; 1 \mathrm{~h}, 25 \mathrm{~min}, 1 \mathrm{sec}$; and $3 \mathrm{~h}, 30 \mathrm{~min}, 0 \mathrm{sec}$ on Trials 3,7 , and 16 , respectively. In Group 2, Subject 1 had a duration of $1 \mathrm{~h}, 27 \mathrm{~min}$, and $49 \mathrm{sec}$ on Trial 2, and on Trial 5, $1 \mathrm{~h}, 15 \mathrm{~min}$, and $1 \mathrm{sec}$. The longest trial for Subject 19 in Group 2 occurred on Trial 2, which had a duration of $1 \mathrm{~h}$, $4 \mathrm{~min}$, and $2 \mathrm{sec}$; its next longest was Trial 9, with a duration of $36 \mathrm{~min}, 4 \mathrm{sec}$. Subject 22 in Group 2 had one long-duration trial of $1 \mathrm{~h}, 10 \mathrm{~min}$, and $23 \mathrm{sec}$, occurring on Trial 10. Subject 18 in Group 2 had no durations longer than the $20 \mathrm{~min}, 12 \mathrm{sec}$ occurring on Trial 2, but it had durations of $10 \mathrm{~min}, 40 \mathrm{sec}$ on Trial 7, and $14 \mathrm{~min}, 58 \mathrm{sec}$ on Trial 14. Only in Group $3 \mathrm{did}$ there appear to be a distribution of long-duration trials early in the total sequence, and this was due primarily to two subjects. Subject 12 had a duration of $1 \mathrm{~h}, 4 \mathrm{~min}, 7 \mathrm{sec}$ on Trial 1, and $23 \mathrm{~min}, 36 \mathrm{sec}$ on Trial 2. Subject 9 had a duration of $3 \mathrm{~h}$, $6 \mathrm{~min}, 55 \mathrm{sec}$ on Trial 1 and $1 \mathrm{~h}, 39 \mathrm{~min}, 2 \mathrm{sec}$ on Trial 2. Subject 6 in Group 3 had a duration of $43 \mathrm{~min}, 45 \mathrm{sec}$ on Trial 1. Subject 23 in Group 3 had a duration of $8 \mathrm{~min}, 43 \mathrm{sec}$ on Trial 1. These were the trials of longest duration, and the remainder of the trials appear to be rather randomly distributed around smaller values for all of the subjects in Group 3.

The resultant effect, typical of tonic immobility studies, is to produce standard deviations for all three groups that are greater than their respective means. Gallup, Nash, and Wagner (1971) have described procedures for investigating tonic immobility in chickens, in which they employ preliminary habituation to reduce such variability; however, they still find it necessary to use square root and $\log _{10}$ transformations to reduce variability. In such studies the means are still smaller than the standard deviations. Gallup has also provided extensive support for fear as a basic correlated factor accompanying tonic immobility (Gallup, 1974, 1977). According to this viewpoint, increased durations are the result of increased fear states. The overall results of the present experiment would seem to indicate that massing of trials produced a greater and more prolonged fear state, whereas relative spacing permitted fear dissipation over the 24 trials. It would appear, at first blush, difficult to account for the dispersion of longer durations across trials for individual subjects in the present study, that is, why "fear" is elicited dramatically on some trials and not on others. Such a finding possibly could be attributed to a confounding of the efficiency of inversion on each trial and the degree to which the individual subjects were able to observe the presence of the experimenter. Nevertheless, the variability within subjects across trials found in the present study is not atypical of tonic immobility studies, and it does remain problematic how one is to meaningfully infer what is meant by "fear" in the tarantula.

\section{REFERENCES}

Crawford, F. T., \& Prestrude, A. M. (Eds.). Animal hypnosis: Research and theory. Psychological Record, 1977, special issue.

GalluP, G. G., JR. Animal hypnosis: Factual status of a fictional concept. Psychological Bulletin, 1974, 81, 836-853.

GalluP, G. G., JR. Animal hypnosis: The role of fear and predation. In F. T. Crawford \& A. M. Prestrude (Eds.), Animal hypnosis: Research and theory. Psychological Record, 1977 , special issue.

Gallup, G. G., JR., Nash, R. F., \& Wagner, A. M. The tonic immobility reaction in chickens: Response characteristics and methodology. Behavior Research Methods \& Instrumentation, 1971, 3, 237-239.

Gilman, T. T., \& Marcuse, F. L. Animal hypnosis. Psychological Bulletin, 1949, 46, 151-165.

KLEMM, W. R. Neurophysiologic studies of the immobility reflex ("animal hypnosis"). In S. Ehrenpreis \& O. C. Solnitzky (Eds.), Neurosciences research (Vol. 4). New York: Academic Press, 1971.

RABAUD, E. L'immobilization réflexe et l'activité normale des arthropodes. Bulletin Biologigue de la France et de Belgique, $1919,53,1-149$.

RATNER, S. C. Comparative aspects of hypnosis. In J. E. Gordon (Ed.), Handbook of clinical and experimental hypnosis. New York: Macmillan, 1967.

Ternes, J. W. Circadian susceptibility to animal hypnosis. In F. T. Crawford \& A. M. Prestrude (Eds.), Animal hypnosis: Research and theory. Psychological Record, 1977, special issue.

Volgyesi, F. A. Hypnosis of man and animals (2nd rev. ed.). Baltimore: Williams \& Wilkins, 1966.

(Received for publication May 23, 1979.) 